\title{
Branchiomyces-like infection in a cultured tilapia (Oreochromis hybrid, Cichlidae)
}

\author{
I. Paperna ${ }^{1, *}$, M. Smirnova ${ }^{2}$ \\ 'Department of Animal Sciences, Faculty of Agriculture of the Hebrew University of Jerusalem, Rehovot 76100, Israel \\ ${ }^{2}$ The Central Fish Health Laboratory, Nir David 19150, Israel
}

\begin{abstract}
A Branchiomyces-like fungus was identified from histologically examined gills of juvenile red tilapia Oreochromis niloticus $\times O$. mossambicus and green tilapia $O$. niloticus $\times O$. aureus obtained from intensive fish farms in Israel. Hyphae embedded in the gill tissue contained undivided and sporulating stages. In one instance infection appeared to be subclinical, limited to one or a few loci in the gill filament and causing only localized tissue damage. In the second case, infection, which was severe and caused extensive tissue damage, was identified in fish from a stock suffering massive mortality which resulted in the loss of $85 \%$ of the pond fish
\end{abstract}

KEY WORDS: Branchiomyces · Gills - Oreochromis hybrid Cichlidae - Mortality A Aquaculture - Israel

This is the first report of branchiomycosis in farmed tilapia. Infection was first diagnosed in histological sections from gills of randomly examined juvenile $(\sim 3 \mathrm{~g})$ red tilapia hybrid (Oreochromis niloticus L. $\times O$. mossambicus Peters) from a fish farm in the Jordan valley, Israel, in July 1985. The second instance of branchiomycosis was diagnosed following an outbreak of morbidity in September 1996 among juvenile $(\sim 7 \mathrm{~g})$ green tilapia (O. niloticus $\times O$. aureus Steindachner) stocked in an earth pond on a fish farm in the same region. This disease outbreak resulted in the loss of $85 \%$ of the pond fishes. Likewise, an infection agent was diagnosed from histological sections of gills prepared from moribund fish.

Materials and methods. Tissue samples, including gills, were fixed in $10 \%$ neutral-buffered formalin for histology immediately after the fish had been decapitated. Tissues were fixed and embedded in glycolmethacrylate (GMA, Agar Scientific Ltd, Stansted,

·E-mail:paperna@agri.huji.ac.il
UK). Sections $(2-3 \mu \mathrm{m}$ thick) were cut in a Sorval JB4 glass-knife microtome and stained in Meyer's haemalum-eosin.

Results. Branchiomycosis could not be recognized from an external examination of whole gills, even in the severe infections, but it was readily detectable by histological examination. In histological sections the filament portion of the gills contained a variety of developing stages of a Branchiomyces-like fungus. Infection was limited to one (in the case of mild infection) or several filaments, with the remainder left intact. Infection was localized in the filamental epithelial layer, which proliferated in heavily infected fish (Fig. 1).

Single, hard-walled sporangium-like bodies of about $21 \mu \mathrm{m}$ in diameter containing several nuclei bordered the blood vessels (Fig. 2). Hyphae of up to $11 \mu \mathrm{m}$ in diameter at the onset of sporulation contained multinucleate plasmodia with a foamy cytoplasm (Figs. 3 \& 7 a). These divided into single-cell bodies, $6-7 \times 5-6 \mu \mathrm{m}$ in diameter (Figs. 3 \& 7b). Plasmodial bodies (which appeared to be daughter stages) containing several nuclei, each with an oblique marginal nucleolus, contained more condensed cytoplasm with numerous faintly eosinophilic granules. Some of these plasmodia, aggregated within an intercellular space with necrotic matrix margins, extended branching outgrowths into the peripheral cytoplasm (Figs. $4 \& 7 \mathrm{c}$ ). Other sections of hyphae contained numerous 6-8 ×6-7 $\mu \mathrm{m}$ uninucleate or binucleate bodies at various stages of differentiation (sporonts), with a thin and hard wall, and with either many vacuoles or a dense cytoplasm (Figs. 5, 6, 7d, e, 8, $9 \& 10$ ). Among these, some were plasmodium-like (non-transformed progeny of the large plasmodia?), thin-walled, and apparently also branching (Figs. 4, 6, $9 \& 10$ ). Cross-sections also contained similar-size bodies with a hard wall or dense 




Figs. 1 to 6 . Oreochromis spp. Fig. 1. Heavily proliferated gill filaments due to branchiomycosis next to unaffected filaments (arrows: hyphae loaded with sporonts) $(\times 150)$. Fig. 2. Multinucleate sporangium-like body bordering a blood vessel $(\times 1050)$. Fig. 3. Hyphae containing (a) a multinucleate plasmodium or (b) division progeny of single-nucleus bodies with foamy cytoplasm $(\times 1050)$. Fig. 4. Branching 'daughter' plasmodia (see drawing, Fig. 7b) ( $\times 750)$. Fig. 5. Section through (a) non-differentiated hyphae; (b) hyphae loaded with progeny of plasmodia (sporonts) at various stages of differentiation (arrow: thin-walled sporonts, or 'daughter' plasmodia); adjoining area (c) of epithelial degradation pyknosis, karyorrhexis, with infiltration of leucocytes $(\times 750)$. Fig. 6. Cross-section of hyphae loaded with soft- and hard-walled sporonts (fine and bold arrows, respectively) ( $\times 750$ ) 
matrix, containing many nuclei (up to 13 per section) or already in the process of plasmotomy, i.e. division into uninucleate offspring (Figs. $7 \mathrm{f}, 8 \& 10$ ). In the latter bodies ( $6 \times 8 \mu \mathrm{m}$ in diameter) the nuclei further divided to form numerous spores $\sim 1 \mu \mathrm{m}$ in diameter (Figs. $7 \mathrm{~g}$, 11, 11a \& 12). The end products of the sporulation process were seen either enclosed in their parent cell wall within the hyphae (Fig. 11) or in the process of dispersal (Fig. 12). When spread into the surrounding tissue, they also became aggregated within large macrophage-like cells with a marginal, flattened nucleus (Fig. 13). Hyphae filled with these sporulating bodies were seen emerging through the surface of the gill filament, enabling spore dissemination to the external environment (Fig. 14). It could not be ascertained from the cross sections if these extending hyphae were branched. Single cells loaded with spores occurred in the epithelial layer outside the hyphal perimeter (Fig. 15).

The emerging hyphae spread infective material into the water, while released spores and whole sporulated sporangia, which were phagocytized by macrophages,

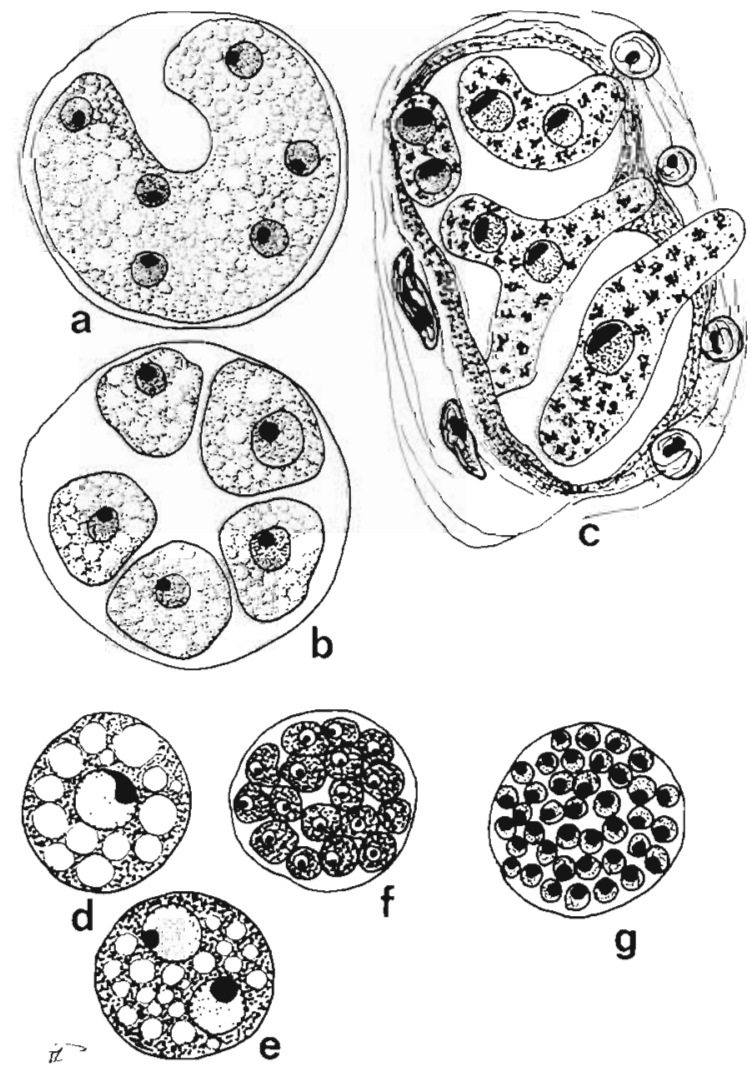

Fig. 7. Drawings of stages in the differentiation of the Branchiomyces-like fungus from Oreochromis spp. (a) Plasmodium. (b) Uninuclear progemy of the plasmodium. (c) 'Daughter' plasmodia extending into the surroundings of their hypha (d, e) Single and bi-nucleate 'sporonts'. (f) Divided 'sporont'

(g) 'Sporont' at final stage division, filled with spores apparently disseminated the infection to new loci in the same host. Daughter plasmodia growing out from their hyphae apparently aid in expanding the area of infection within the gill filament.

Active heavy infection induced extreme epithelial proliferation. The proliferated epithelial cells were organized into concentric layers around the fungal hyphae (Fig. 15). The hyphal wall was embedded in a narrow layer of homogeneous matrix, apparently an end product of local cellular necrosis (Fig. 5). Signs of localized cellular damage (including spongiosis or cellular degeneration, karyorrhexis and pyknosis) were also evident throughout the epithelial layer (Figs. 5 \& 9). The proliferated epithelium was infiltrated by erythrocytes and macrophages (Figs. 1 \& 5). Bases of some gill filaments were intensively infiltrated by lymphocytes and macrophages. In the severely infected fish, some entire filaments underwent complete degeneration or necrosis, and remained filled with debris of epithelial cells and erythrocytes containing karyorrhexis and pyknotic nuclei. Such filaments contained necrotic residues of the fungus, as well as a seemingly active hyphae (Fig. 16); the filament's edges had been invaded by bacteria.

Discussion. Infection occurs in the epithelial layer, though it could expand from an initial infection in the underlying connective tissue or blood vessels. A similar epithelial Branchiomyces-like infection has been recently found in an Amazonian loricariid (Baryancistrus sp.; I. Paperna \& D. Dicare unpubl. data): the hyphae and the sporonts were of similar dimensions, yielded a similar minute sporulation end product, and in both cases hyphae extended above the gill filament surface. In this fungus, initial germinating spores were found inside the vascular lacunae of the branchial lamellae.

Findings, being restricted to histological data, permit only a tentative diagnosis. The mycotaxonomy of Branchiomyces continues to be a mycologist's enigma. Despite evidence that the fungus may be isolated into culture (Neish \& Hughes 1980), resulting data on its asexual reproductive structures have been inadequate for a conclusive mycotaxonomic analysis, even at the generic level (Alderman 1982). Only 2 species of Branchiomyces have been characterized to date. Of these, $B$. sanguinis Plehn develops in association with the gill vascular system in carp Cyprinus carpio, whereas $B$. demigrans Wundsch in tench Tinca tinca and pike Esox lucius extends to the epithelial layer (Neish \& Hughes 1980) and hyphae, similar to that observed in the presently described infection, extend to the surface of the filament. Spore sizes of these 2 species, 5-9 $\mu \mathrm{m}$ and 12-17 $\mu \mathrm{m}$ respectively, grossly differ from the minute spores $(\sim 1 \mu \mathrm{m})$ observed in the fungus described as well as in the infected Amazonian loricariid. 


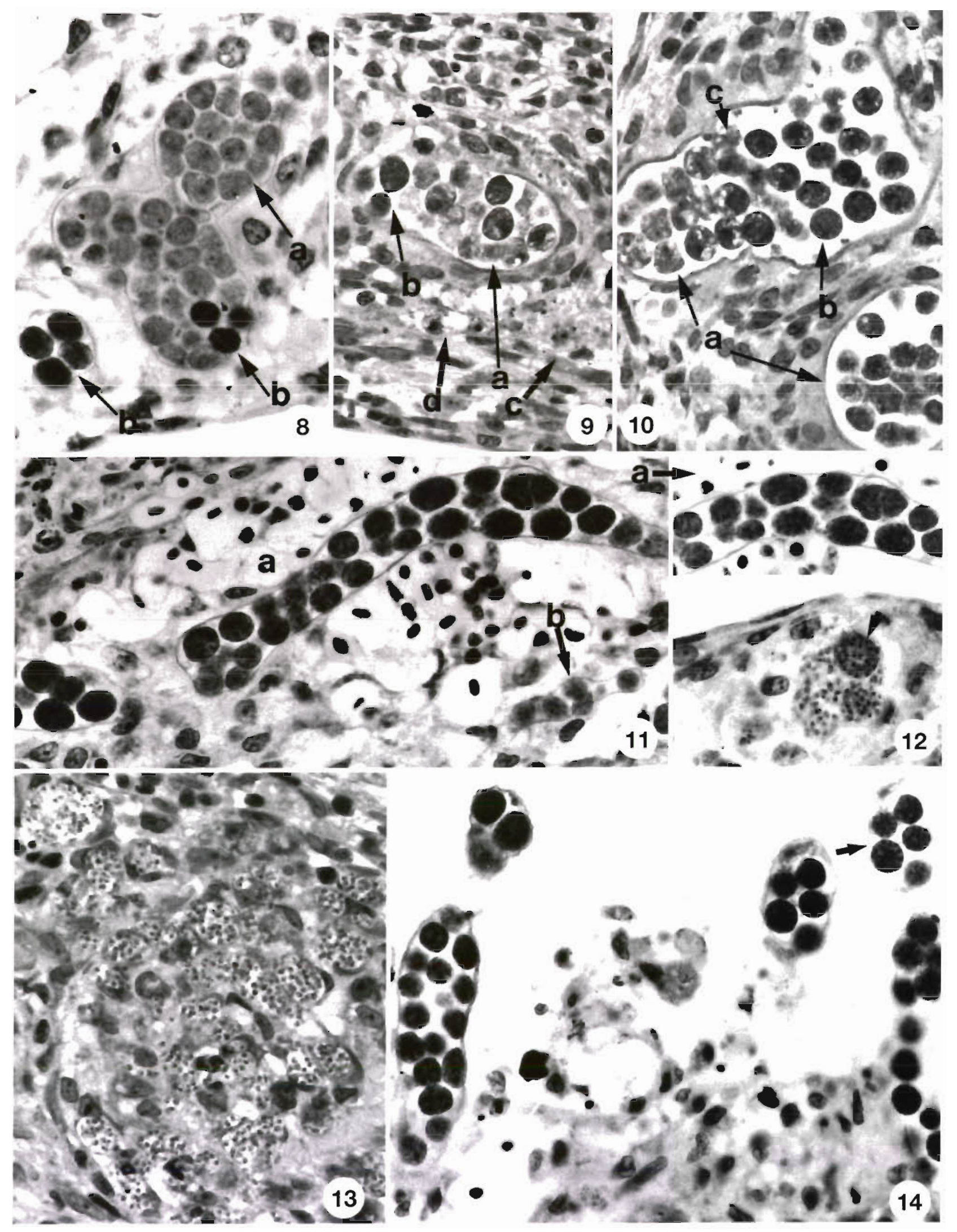


Figs 8 to 14. Oreochromis spp. Fig. 8. Hyphae containing (a) uninucleate and binucleate progeny of plasmodia and (b) divided sporonts $(\times 1050)$. Fig. 9. Hypha containing thin-walled 'daughter' plasmodia (a) and dividing bodies (sporonts) (b); the epithelial tissue contains degeneration loci (c) and the remains of defunct hyphae (d) ( $\times 750)$. Fig. 10. Hyphae (a) with sporonts at various stages of differentiation (b) and a few daughter plasmodia (c). Fig. 11 Longitudinal section of a hypha (a) containing divided sporonts (detailed section to right: lower-density image enabling a better view of the divided bodies); (b) a degenerate hypha $(\times 1050)$. Fig. 12. Spores, scattered and contained within a sporont (arrow) $(\times 1050)$. Fig. 13. Spores contained within phagocytic cells in the filamental epithelium $(\times 1050)$. Fig. 14. Hyphae containing spore-loaded sporonts (see inset) emerging from the gill filament $(\times 1050)$

Branchiomyces infections, often with severe consequences to fish, have been reported in Europe from carp, tench, pike (Neish \& Hughes 1980) and Silurus glanis (Danko et al. 1967) as well as from eels Anguilla japonica in the Far East (Equsa \& Ohira 1972, Chien et al. 1978). This is the first reported case from cichlid fishes. Branchiomycosis is potentially very pathogenic to fish, and difficult to control (Neish \& Hughes 1980). The eutrophic conditions often prevailing in warm-water, intensive tilapia culture systems seem to provide a favorable environment for the proliferation of this fungus (Paperna 19961.
Acknowledgements. This research was supported by grant no. 5423-2-96 from the Ministry of Science, Israel.

\section{LITERATURE CITED}

Alderman DJ (1982) Fungal disease of aquatic animals. In: Roberts RJ (ed) Microbial diseases of fish. Soc Gen Microbiol, Academic Press, New York, p 189-242

Chien CH, Miyazaki T, Kubota SS (1978) The histopathology of branchiomycosis of eel in Taiwan. JCRR Fish Series (Taiwan) 34:97-98 (in Chinese, English abstract)

Danko G, Szabo J, Szakolczai J (1967) Die Kiemenfäule bei Welsen (Silurus glanis). Zentralbl Bakteriol Parasitkde Abt II 121:523-531
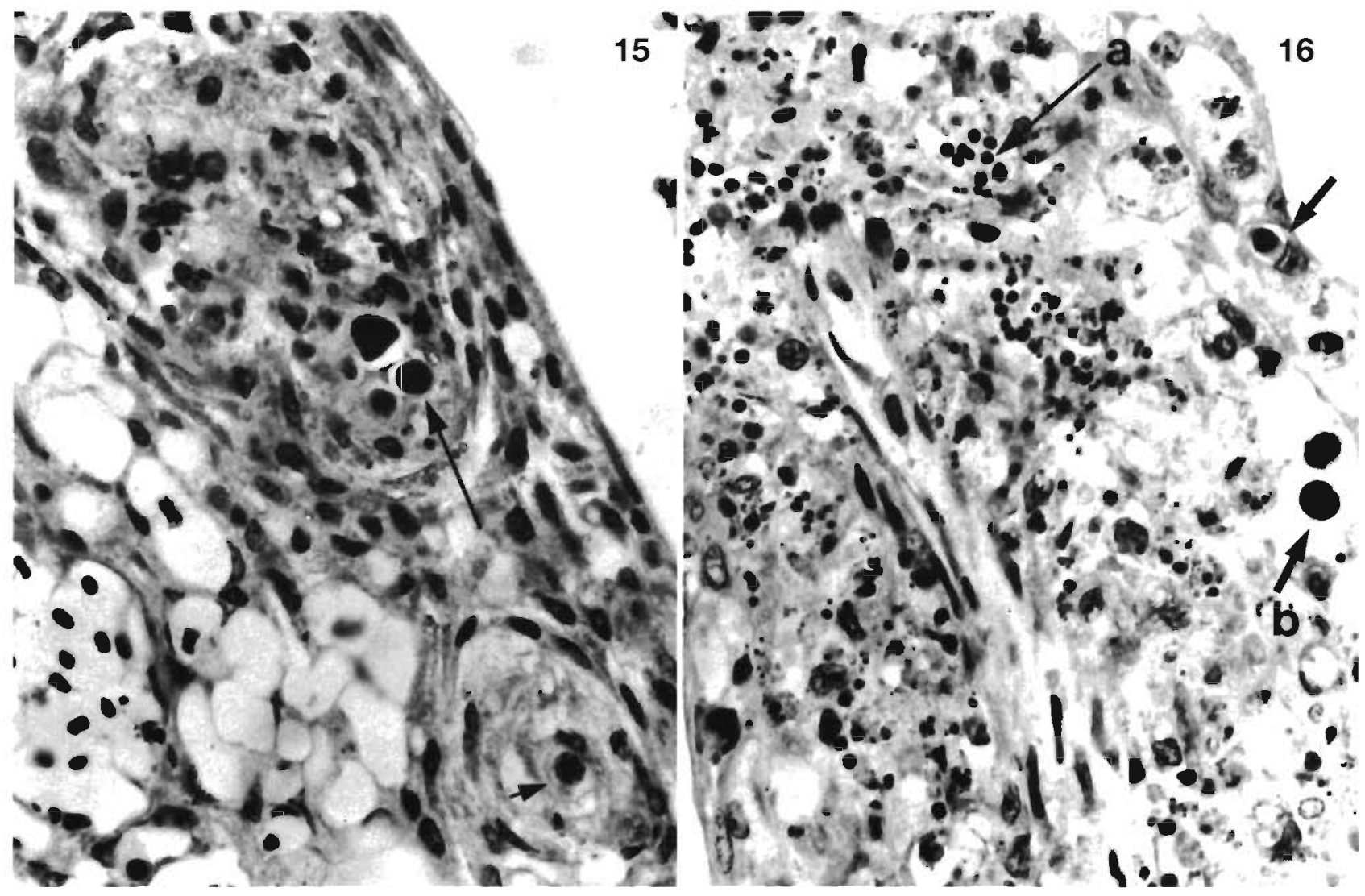

Figs. $15 \& 16$. Oreochromis spp. Fig. 15. Concentric proliferation of the filamental epithelial tissue around the fungal remains $(\times 750)$. Fig. 16. Branchiomycosis-induced necrosis of the gill filament with (a) residues of congestion and (b) some remains of fungal sporonts $(\times 750)$ 
Egusa S, Ohira Y (1972) Branchiomycosis of pond-cultured eels. Fish Pathol 7:79-83

Neish GA, Hughes GC (1980) Disease of fishes. In: Snieszko SF, Axelrod HR (eds) Fungal diseases of fishes. Book 6.

Editorial responsibility: David Bruno,

Aberdeen, Scotland, UK
TFH Publ, Neptune, NJ

Paperna I (1996) Parasites, infections \& diseases of fish in Africa, an update. CIFA Technical Paper No. 31, FAO Rome

Submitted: June 23, 1997; Accepted: October 29, 1997 proofs received from author(s): December 22, 1997 